\title{
Urban Development and Governance in Nigeria: Challenges, Opportunities and Policy Direction
}

\begin{abstract}
Volumes of literature discourse illuminate several weaknesses of Nigeria's urban planning and governance system particularly in the face of rapid urbanisation, and rising levels of urban poverty and informality. However, these literature discourses often fail to situate the weaknesses within the context of opportunities presented by the system, and provide a clear policy direction. An in-depth understanding of the weaknesses of the system, and opportunities it presents especially for the on-going construction of massively scaled urban developments to meet demands of various urban actors and their impact is imperative for far reaching policy formulation and implementation. Based on an examination of the perspectives of key urban stakeholders solicited through semi-structured interviews in three Nigerian cities of Abuja, Minna and Enugu, this study provides insights into how the failings of the existing regime provide opportunities for the urban developmental landscape. The findings suggest that pluralistic forms of social steering in urban planning and governance have the potential to succeed. Nevertheless, Government input especially in the area of infrastructure provision is critical.
\end{abstract}

Keywords: Development, governance, Nigeria, planning, urban

\section{Introduction}

Cities in Africa face a number of challenges, such as poor housing and environment conditions, and huge infrastructure and services deficit. Concurrently, the region continues to experience rapid urban growth and urbanisation, which are occurring under varying economic conditions. Africa's urbanisation rate was $40 \%$ as at 2011 . This will soar to $60 \%$ by 2050 (UN-Habitat, 2014). There is, therefore, an increasing concern that urbanisation rates in the region have 
outrun the capacities of constituent states to provide developable lands, affordable housing, and access to infrastructure and services. Urban planning and governance systems in the region, which are supposed to help redress the situation, have also proven to be weak and ineffective.

Nigeria is one country in Africa that mirrors the continent's urban challenge. A major characteristic of this challenge is the massively scaled urban developments' taking place under several guises. These developments often labelled as formal and informal seek to meet the demand for urban accommodation, businesses and services from diverse population, and reflect massive divisions between the affluent and the poor. Thus, although a challenge, the on-going urban planning and development practices also present opportunities for the construction of many urban developments. For instance, the informal land market provides avenues for the majority of the urban population in Nigeria to access developable lands and housing (Oloyede et al., 2011). Nevertheless, the literature discussions on the subject tend to focus on the ills of the extant urban planning and governance system. This often focuses on the massive disparity between the on-going developments for the affluent and the urban poor. This implies that the literature discussions often occur outside the opportunities that the existing situation offers. The current discourses are also usually devoid of clear policy directions to remedy the challenges. However, such clear policy direction requires an understanding of the current situation, and its challenges and opportunities.

This study ${ }^{1}$ seeks to contribute to the provision of an understanding of the on-going urban development and governance practices in Nigeria, their challenges, opportunities they offer and provide some insights for policy formation. It drew on interview survey of urban sector

\footnotetext{
${ }^{1}$ The study was part of the baseline work for the UK's Department for International Development (DFID) Urbanisation and Infrastructure Research and Evaluation Manager Programme.
} 
stakeholders in three Nigerian cities of Abuja, Minna and Enugu. In so doing, the study first discusses Nigeria's urban planning and governance. Forms of urban development follow this. Thereafter, the methodology for study, and the research findings and their discussions are presented before conclusions with insights for policy formulation are drawn.

\section{Urban Planning and Governance in Nigeria}

The narrative of urbanisation in Nigeria often focuses on multiple issues especially the increasing incidence of adverse urban environmental outcomes and the inability of urban planning to address the underlying causes. Similar to the majority of Sub-Saharan African (SSA) countries, the often-cited challenges of Nigeria's urban environment include rising levels of urban poverty and inequality, inadequate access to formal lands for development, proliferation of informal settlements, and the lack of basic infrastructure and services (Ogbazi, 2013). However, consensus within the growing body of literature identifies the core link of the problem to the weaknesses of urban planning and governance system in the country (Egbu et al., 2008; Ogbazi, 2013). For example, according to the World Bank (2014, 2017), Nigeria is one of the lowly ranked countries across the globe in terms of delays and financial cost relating to processing of construction permits and registration of land rights. Such delays and cost partly account for non-compliance with planning and urban development regulations, which ultimately lead to adverse environmental outcomes (Egbu et al., 2008).

The debate on the exceptional failings of Nigeria urban planning and governance system often reflects a number of imperatives as critical causes. These are tensions between traditional and formal sector actors, and among national, state and local governments in particular, mismatch between political jurisdiction of state and local governments in relation to city or regional economies. The remainder is resource curse and corruption, as well as other factors, such as 
inadequate resources both human and material. Formal urban planning and land administration practices were introduced in the country during the colonial epoch. Successive post-colonial administrations have virtually not departed from the colonial planning and land administration provisions, and in some cases have even entrenched them. There have been two major laws relating to land administration and urban planning since the colonial planning legislation (Town and Country Planning Ordinance (1946)). These are the Land Use Decree (now Act) (1978) and the Urban and Regional Planning Decree (now Act) (1992) with its subsequent revisions. However, the philosophy of the colonial planning ordinance still drives these laws. In particular, these laws continue to enjoin planning to follow the centralised technocratic and bureaucratic processes and procedures, as well as the restrictive demands of the colonial ordinance. Commentators (Ogu, 1999, 2002; Ogbazi, 2013) note that these processes and procedures do not promote inclusion, and tend to exclude the majority of the urban sector stakeholders from the planning processes. Therefore, the formal urban planning and land administration practices over the years have largely been divorced from the culture and traditions of the country (Chorkor, 1993; Ogbazi, 2013).

The literature also highlights the inadequacies of the formal urban land administration, planning and governance system(s) at the local level. For example, the literature notes the lack of clarity of mandate for the several government bureaucracies involved in land rights formalisation (Agunbiade and Rajabifard, 2013; Adeniyi, 2013). The Land Use Act (1978) vests urban lands in state governors and converts old forms of estate into rights of occupancy. This means that an existing right of occupancy has to be covered by a Certificate of Occupancy (C of O) issued by state governors (Ikejiorfor et al., 2004). Further, the Act together with the Urban and Regional Planning Act have made state and quasi-state institutions like local governments responsible for survey, planning and provision of infrastructure, as they have to 
ensure that urban lands are properly surveyed, planned and serviced. However, as noted previously the institutions are constrained by complicated processes (Egbu et al., 2008) and are required to deal with a contradictory legal framework (Adeniyi, 2013; Deininger et al., 2014). In addition, Nigeria's on-going urbanisation is not limited to major urban centres, but they are also occuring across small towns (UN-Habitat, 2010; Ogu, 2010). A prominent feature of the growth is the expansion of urban centres to encompass adjoining rural or peri-urban settlements thereby creating a problem as to the body, state or local government that has the jurisdiction by way of planning over such transitional areas (Adams, 2016).

Following the discovery of oil in the 1950s, Nigeria's economy gradually transformed from one based on agriculture to one solely dependent on petroleum (Ogu, 2010; Idemudia, 2012). Although increases' in Government revenue from oil is necessary for socio-economic development, Nigeria's reliance on the resource to the neglect of other sectors, such as agriculture has made the country vunerable to fluactions in world market oil prices. Besides, the boom in the oil sector has not reflected in the lives of the majority of the people. On the contrary, it has partly led to deteriorating socio-economic conditions and corruption (Ogu, 2010; Idemudia, 2012). It has also contributed substantially to the on-going urbanisation in the country as people relocate to state capitals, and major cities and towns in search for non-existent white-colar jobs (Ogu, 2010). The majority of these migrants, therefore, resort to alternative forms of livelihood especially in the informal sector accounting partly for the rising levels of urban informality. This has increased the pressure on existing infrastructure in the face of weak urban authorities and inadequate financial resources for both state and urban governments to design and implement effective urban programmes (Ogu, 2010). This is accentuated by state governements ianbility to mobilise revenue outside of federal govrnment's allocation mostly from oil revenue (Adams, 2016). 
Corollary to the above is planning and land admistration institutions lack of capacity to fully execute their functions resulting in problems, such as out of date city plans (Aribigbola, 2007) and paucity of data. This hampers land development activities including land acquisition and formalisation processes because adequate surveys and demarcation of urban lands have not been undertaken on a widespread basis. The literature further identifies other challenges including: the lack of coordination among palnning institutions (Ogu,1999); widespread apathy to adopt modern planning theories and models (Ogbazi, 2013); the absence of strategic plans; failure to implement and enforce detailed land use plans (Gandy, 2005; Bloch, 2014; Sawyer, 2014), and the lack of large scale utilisation of modern digital technology to facilitate planning and land administration processes (Akindgbade et al., 2012).

\section{Forms of Urban Development}

The inadequacies of Nigeria's urban planning and governance system have culminated in several problems. The reliance on manual processes and procedures has led to further delays with processing of relevant documentations, and ultimately high cost of compliance with development regulations and low compliance rate (Egbu et al., 2008; World Bank, 2014). Also, the system's exclusion of urban sector stakeholders in planning processes has contributed to a lack of awareness of the urban development regulations, processes, transparency and legitimacy, and partly the low compliance rate with development regulations (Ogu, 1999; Aribigbola, 2007). Consequently, urban planning authorities are often seen as "alien" authorities by these communities rendering the communities at times unreceptive to modern planning arrangements, such as re-development or renewal proposals. 
Coupled with a fourfold increase in population since the 1950s, Nigeria's urban planning challenges have further culminated in a complex urban situation with a number of urban ills. However, a prominent outcome from the challenges is the emergence of two forms of developments namely formal and informal. Formal developments are developments produced through the formal urban development processes. Conversely, informal developments are alternative forms of developments. They emerged from the informal urban development and governance system. This is often equated to the customary land delivery and development system, which predates the formal urban development system (Ikejiofor, 2006; Baffour Awuah, 2016). Unlike formal developments often described as adequate and suitable, the traditional notion of informal developments is one of being illegal developments characterised by poor quality construction materials and often located in places of poor environmental quality (Wekesa et al, 2013). However, there are many higher quality developments in better neighbourhoods that could be classified as informal because they do not comply with formal processes.

Like other SSA cities, the incidence of informal developments in Nigerian cities continue to increase (Rakodi, 2007; Eko et al., 2012; Abubakar, 2014). However, these developments are often criticised as nuisance particularly by authorities and the elite. Whilst the physical environments delivered through the formal urban development channels are mostly planned and provided with infrastructure and services, informal developments are perceived to be unplanned and not provided with infrastructure and services. Consequently, there is often a lack of development control resulting in breach of development regulations, connection to substandard infrastructure, and losses in government revenues (Rakodi, 2007; Nkuruziza, 2008; Ikejiofor, 2009). Also, activities under the informal land delivery and development system are 
often not documented (Rakodi, 2007; Nkuruziza, 2008). This sometimes leads to multiple sales of the same parcels of land, a potential threat to security of title to lands and developments.

However, some analysts (Rakodi, 2007; UN-Habitat, 2010, 2014) suggest that these developments constitute the largest proportion of all urban developments in Nigeria and are the main source of accommodation for housing and other activities for the majority of urban residents. For example, smaller scale infilling within urban centres and small to medium scale development at the expanding edges of the cities are often realised through informal means and outside the formal planning system (Sawyer 2014). The proliferation of these developments is driven mainly by the inadequacies of the formal development system and the benefits of the informal development system.

Unlike formal development system, the informal development system is more flexible. This potentially makes it more responsive to the needs of the majority of the urban population in terms of expeditious provision of developable lands, document processing and land developments. For example, Aribigbola (2007) reports that as at 2006-2007, the number of residential layouts approved in the city of Akure under the informal development system was 641 compared to those approved by public institutions, which were 20 . However, the problem with some of the planning schemes prepared for informal developments is their inability to incorporate the broad socio-economic development vision of urban areas and their regions. Also, there may always be the likelihood for customary or informal land owners to overlook some ancillary land uses, such as community parks and green belts due to profit considerations or perceptions of their irrelevance.

Nevertheless, the practices adopted to deliver lands and development are sometimes implemented with the assistance of public officials, either legally or illegally. Ikejiorfor et al. 
(2004),identified such practices in Achara in Enugu, where the local planning authority was contacted by the customary landowners to prepare a planning scheme for the the community. Also, the system is currently developing workable mechanisms for such purpose. According to Ikejiorfor et al. (2004) an informal information system exists, which ensures that members of the public become aware of available lands for sale, and ascertainment of the roots of title to the lands. This information is often channelled through relatives and friends of land owners and local land brokers. Land owners engage local surveyors who survey their land and mount beacons to separate the boundaries of different parcels. Furthermore, allocation notes are given to purchasers of land with various agreements, which are witnessed by community leaders, and conflict over land ownership and development protocols resolved by community elders. This corroborates similar mechanisms in cities, such as Kampala in Uganda (Nkurunziza, 2008) and Bahir Dar City in Ethiopia (Adam, 2014). A setback to these mechanisms is that they tend to crumble in the face of increasing urbanisation and rising demand for land (Ikejiorfor, 2006). However, recent evidence shows that with rapid urbanisation and commodification of land, affluent women could acquire their own lands for development (Ikejiorfor et al., 2004; Ikejiorfor, 2006). This is an improvement on previous situation where women access to land was limited due to customary restrictions. Conversely, they have tended to limit the poor's access to land due to escalating prices (Ikejiorfor, 2006).

The urban growth in Nigeria demonstrates that considerable resources channelled largely through informal processes lead to increased wealth for some sectors of society. Also, despite the limitations of the informal development system, it appears to offer a great deal of benefit to the majority of the Nigerian urban population. Experts have proposed pluralistic urban planning, development and governance paradigms that emphasise multi-level processes and procedures based on engaging community level action, civic leaders, Non-Governmental 
Organisations (NGOs) and the private sector to deliver sustainable solutions (Ogu, 1999, 2002; Ogbazi, 2013; UN-Habitat, 2014). However, in spite of investment by NGOs and development agencies in city planning and development strategies, for example, the introduction of new policy initiatives and programmes, such as the Sustainable Cities Programme (SCP), the integration of such stakeholders in formal processes is poor and continues to generate tension (Ogbazi, 2013). This implies a need for a further understanding of opportunities and challenges under the existing arrangement(s) to capitalise on the strengths and weaknesses of formal and informal systems for far reaching policy solutions.

\section{Methodology}

A literature review of Nigeria's urban planning and governance arrangements was conducted. This provided background insights for systematic implementation of the study. The review also identified key urban sector stakeholders in Nigeria's urban development processes. Based on this information and data obtained from some key informants, such as the local presidents of the Nigerian Institute of Town Planners and local government officials, stakeholder mapping and analysis were undertaken to determine the research participants. The literature review, thus, helped to contextualise and direct the implementation of the research, as well as the design of the data collection instruments.

Following the literature review, semi-structured interviews were conducted with key urban sector stakeholders in three Nigerian cities of Abuja, Minna and Enugu. The stakeholder mapping and analysis carried-out identified four main stakeholder groups namely: the public sector agencies; community/civic leaders and NGOs/ Community-based Organisations (CBOs); private sector and professional bodies. For ease of reference, the public sector agencies' henceforth is referred to as Government. The other stakeholders: community/civic leaders and NGO/CBOs; private sector; and professional bodies are also referred to as civic 
leaders, private sector and professional bodies respectively. Government comprised relevant officials of Government ministries, department and agencies, such as land, survey and town planning institutions whilst that of civic leaders' consisted of community heads, and leaders of CBOs and NGOs. The private sector focused on commercial real estate developers. Lastly, professional bodies drew on practising members of professional bodies like the Nigeria's Institutes of Town Planners, and Surveyors.

Twenty-four interviews were conducted, eight from each of the three cities. Two participants were selected from each of the stakeholder groups. The selection was based on insights from the purposive sampling technique due to the qualitative nature of the study and the lack of a reliable sample frame. However, with the help of the relevant informants the selection of the participants took account of the knowledge and experience of participants, among others. Given the qualitative nature of the study and the capability of the research participants to provide the required information to deliver the research, the sample size and selection technique were deemed appropriate for the study.

The selected cities were also considered suitable to generate the required insights. The study sought to garner these insights from both the northern and southern parts of Nigeria at a time when the country was undergoing serious security challenges particularly in the north. This security challenge together with factors such as incidence of urban development challenges and opportunities, and data considerations including insights from the implementation of the maiden SCP informed the choice of Minna, Abuja and Enugu as case study cities. The interviews were carried-out from October - December 2015. It focused on themes, such as land acquisition, urban planning and development, and formal and informal developments. Outcomes from the interviews were evaluated based on thematic analysis. 


\section{Research Findings}

Findings from this study should be evaluated cautiously. They may not to be comprehensive. However, the connections of the results to urban environmental issues and findings from relevant studies show that they are significant. In broad terms, understanding of the urban planning and governance issues differed across the participant groups. However, this was expected. The findings are categorised into four main headings including challenges and opportunities of Nigeria's urban planning and governance system. These are presented as follows:

\section{Urban Planning and Development}

The findings presented in this section focus on some pertinent urban planning and development issues other than the challenges and opportunities.

\section{Acquisition of Land}

There was a concensus among all the participant groups that formal lands are acquired through Government. Also, formal land registration as the legal perfection of land ownership was universally recognised. However, there were nuances in knowledge of how and why Government is vested with that authority. Government and the private sector participants could state the relevant legislation that empower Government to do so, but such knowledge was sketchy among the other groups of participants. Further, it came to the fore that formal lands could be acquired through subsequent transactions where a beneficiary of formal land sells the land to another person. Government and the private sector participants described clearly the alternative legal processes for acquistion through subsequent transactions. It was striking that participants from the professional bodies could not state the relevant legislation that vest Government with the authority to make land grants for development and clearly descibe the processes involved given that they are professionals in the built environment. However, as 
noted previously, this finding should be interpreted carefully given that the built environment comprise several professions, but only a small proportion of them was involved in this study.

Nevertheless, all the participant groups recognised a contrast between Government land allocation and customary land allocation processes - both of which could lead to formal registration of ownership to land. Further, they noted that registration of lands granted under customary arrangements could result in shorter leasehold terms. This stems from parties to land transactions strategy of back-dating land transfers in order to comply with the provisions of the Land Use Act. The provisions of the Act vest ownership of all lands in the state and that land grants should emanate from Government signifying that such land grants would ordinarily have risked their titles being regularised. This finding corroborates earlier studies, such as Ikejiorfor (2006) who found similar land grant processes and practices, as well as strategies adopted by both vendors and purchasers of land to circumvert the requirements of the Land Use Act in Enugu.

\section{Meaning of Urban Planning}

Differences in perception of urban planning especially between Government participants and those from the professional bodies on the one hand, and the civic leaders and private sector participants on the other hand were noted. The former groups of participants had a comprehensive view of planning and opined that it should include economic, social and environmental issues, as well as involve communities, other stakeholders and deliver infrastructure and services.

Conversely, the later participants expressed a narrower view of planning with some of their explanations, in particular, from the civic leaders showing a lack of understanding. These 
participants largely perceived planning as physical arrangement of land uses and enforcement of rules and regulations to achieve harmonious land use, as well as provision of physical infrastructure. Nevertheless, there was a consensus within all the participant groups that planning in Nigeria is predominantly a Government activity. This finding is in tandem with studies, such as Aribigbola (2007) and Egbu et al. (2008) that observed that planning practice in the country is still informed by colonial legislation, which in many respects make it the preserve of Government and its functionaries to the exclusion of the greater majority of the citizens. However, there was a recognition particularly amongst the civic leaders that there exist indigenous forms of planning across cities in the country. This was referred to as informal planning, which is mostly practiced in informal settlements as formal planning often do not extend to such settlements. Athough visionary master planning and provision of infrastructure were seen as a benefit, the detailed rules and regulations of plans and their enforcement were to a certain extent resented by the civic leaders who were inclined to regard them in some respects as alien interference. This finding also concurs with similar observations made by Ogu (1999) who noted that the resentment is partly due to planning authorities failure to consult with traditional authorities..

\section{Participation in Urban Planning}

Mixed outcomes were gathered on experience relating to community engagement in urban planning. While some members of each of the participant groups expressed that there have been instances where planning authorities have involved communities or the private sector in planning others within each group did not note such experience. Nevertheless, it was recognised that such practices could be useful. A Government participant in Minna, for example, noted as follows: 
Our experience shows that the involvement of stakeholders will enrich the process and product of urban planning. It helps to balance the vision of the State Government with that of the people. The response from the stakeholders also encourages acceptability of the plan.

An example of the Emene community in Enugu where the community, and planning and urban development authorities worked together to prepare planning schemes over lands and arrange for infrastructure and services was given by both civic leaders and Government participants from the city. It was explained that the arrangement was initiated by the community leaders who contacted the local planning authority. Whilst the example demonstrates that such participation could be initiated by communities public authorities need to be receptive to and display honesty and openess in such arrangements for it to be successful. Indeed, these credentials were vital to the Emene community's example, which saw the community benefit from planning schemes and basic infrastructure. The community members were also very receptive to the planning schemes and were eager to comply with their provisions. This supports Ogbazi (2013), which identified similar such success factors in the evaluation of particiption in planning and urban development as part of the maiden sustainable cities programme in Enugu, Ibadan and Kano.

\section{Challenges}

\section{Access to Formal Lands and Preponderance of Informal Developments}

Access to formal lands for development was noted by the majority of the participant groups to be difficult.There were some indications espcially from the civic leaders that the informal land delivery or acquisition process might be preferred by groups and individuals who often feel excluded from the formal land acquisition process. This is due to the shortcomings of the 
formal land delivery processes including delays and high cost associated with the processes. A civic leader in Abuja, for instance, noted that:

When Government acquires land from the community, the community lose. The land becomes property of Government, and Government allocates it the way it wants. That reduces the available quantum of land to that community.

The participant explained that when Government acquires a community's land through compulsory purchase, the extent of that community's land is reduced by the size of the acquired land. Therefore, access to such lands by the community members is lost. The situation becomes worse where compensation for the acquisition is not paid and Government allocates the land without considering members of the community, but rather focus on satisfying the needs of the elite and affluent in society, which often is the case.

It emerged from the interviews that ordinarily there should be ready access to Government land by every Nigerian. However, such is not the case due to the following:

Upon acquisition the lands have to be re-surveyed, zoned and sub-division plans prepared to cover them. This ensures provision for various land uses depending on the needs of the relevant communities. However, these activities usually take a long period of time often between two and five years. This delay was attributed to logistical constraints, lack of adequate co-ordination among relevant Government institutions and the long periods for obtaining requisite approvals, such as Government budgetary approvals. 
Applicants have to apply to land allocation committees for allocations and need to meet certain requirements, such as complete application forms, demonstrate evidence of financial capacity to develop the land and sometimes provide designs for proposed developments. Also, applicants have to pay some statutory fees. Whilst a few people are able to get allocations easily and within a comparatively short period of time, it takes ages for the majority of the people to get allocations. Apart from inadequate resources both human and material, irregular meeting times of the committees, the long period it takes for the allocation committees to make decisions on applications was attributed to manipulations of the elite. Besides, the allocation process is riddled with corruption partiularly extra out of pocket payments to public officials, and follow-ups to Government departments to facilitate the application process. The civic leaders in Abuja disclosed that the period for allocation of land in the city could range between 14 days and 20 years upon submission of application depending on how influential and affluent an applicant is. However, the majority of applicants in most cases do not receive response from the allocation committees. These delays often culminate in depreciation in financial resources developers would have used to finance their projects on the one hand due to inflation and increase in interest on capital payments on the other hand due to the time lag.

The above challenges were echoed by the other groups of participants. A private sector participant in Abuja observed as follows:

Access to formal lands is hindered by the long bureaucracy associated with acquisition. Most often, it takes months or years before an applicant is finally granted a land allocation.

Problems with the Abuja Mass Housing Scheme were cited particularly by the civic leaders, private sector and the participants from the professional bodies to illuminate some of the above 
challenges. They noted that whilst the scheme, which commenced in 2000 was to provide affordable housing to low income housholds through, among others, Government provision of formal lands to the private sector, the allocation procedure for the lands was not followed in most cases. It emerged from the interviews that the elite mostly used their influence in society to acquire more tracts of land than what was allowed and that whilst the maximum allocation ceiling was 10 hectares, some developers were allocated up to 250 hectares of land. Although developers were to mobilise resources and commence development within six months and complete in the third year, most of the alottees did not undertake the developments at all. Rather, they sub-divided the lands and sold them at exorbitant prices, such as between $\$ 3$ million and 6million for $400 \mathrm{~m}^{2}$ land.The majority of the participants agreed that the challenges of formal land acquisition are similar to those associated with planning and development institutions, such as planning authorities and local governments. The participants noted that these institutions also suffer political interference, which affects effective implemention of their functions including enforcement of planning regulations.

Although the above findings are consistent with the findings from the literature (Aribigbola, 2007; Egbu et al., 2008; Akindgbade et al., 2012; World Bank, 2017), the Government participants were rather quick to lay emphasis on political interference in planning, logistical constraints, weak institutions, lack of staff training and inefficiencies as challenges. In contrast, participants from the professional bodies and the private sector, as well as the civic leaders were particular about challenges, such as the cost of compliance with regulations, administrative delays and bureaucratic complexities. The participants noted that a combination of lack of ready access to formal lands, and the above cost and incoveniences are disincentives to compliance, which partly leads to high incidence of informal developments. A private sector participant from Enugu, for instance, observed as follows: 
People engage in informal development because they do not wish to spend money on the expensive and time- consuming process of acquiring a development permit. The cost of securing building permit could get up to $\$ 200,000.00$ for a bungalow. The bureaucratic delay in registration is a big deterrent. Therefore, people prefer to invest their money before it depreciates regardless of the consequence of contravention. To secure building permit, it could take up to two years.

The incidence of informal developments was also partly attributed to non-payment of compensation for Government acquired lands as it has somewhat empowered expropraited owners to encroach on suchlands. It was explained particularly by the civic leaders that such empowerment is bolstered by enabling conditions, such as expropraited community members not having access to formal lands, and Government's inability to utilise all the acquired lands, as well as ensure full scale development control. A civic leader, for instance, said that about 8000 acres of the lands acquired for the FCT were left vacant, a recipe for encraochment especially in a rapidly urbanising city. The participant further mentioned that due to nonpayment of compensation and poor development control, original settlements, such as Gariki, Mabushi Durumi and Gwagwalada Kwali are still occupying their lands although the lands form part of the FCT acquisition.

Opinions, however, differed on whether it is a sensible option to require demolition on the grounds of illegality once a development has emerged informally. This was against the background of rapidly expanding cities where inward migration is culminating in all types of informal practices with economic necessities dictating that extra workers who have diverse and 
conflicting interests are welcome in urban areas resulting often in tensions. It can, thus, be surmised from the discussions that a major hinderance to access to formal lands and low compliance with planning and development regulations is steeped in cost and inconveniences related to the formal land acquisition and development processes. This predominantly include statutory fees paid for the land and the administrative processes, extra out of pocket payments to public officials to facilitate an acquisition process, traveling cost for follow-ups on application processes, waiting times for follow-ups, delays with the acquisition processes and cost of time lag.

\section{The Poor's Access to Lands}

All the participant groups agreed that although there are no deliberate policies that descriminate against the urban poor's access to formal land, it is more difficult for them to access and hold formal lands. Apart from the already discussed difficulties with access to formal lands particularly the financial cost, the participants noted that the problem is due to the poor's lack of awareness of land acquisition procedures and the perception that the poor will not be able to develop any allocated land to the required standard. Therefore, they do not apply for land in good areas. For informal lands, the participants explained that access by the poor is increasing becoming limited due to rising levels of demand and prices. A participant from the professional bodies in Enugu observed that:

Until recently, the local lands were easily affordable to the urban poor due to their low prices. However, the high demand for land has affected the prices and access by the poor.

The above finding corroborates findings from Ikejiorfor (2006). That said, it came to the fore that where the urban poor are allocated formal lands it is often difficult for them to hold on to 
such lands over time especially if these lands are located in prime areas or become prime due to urban growth or positive location externalities. This is because the elite and the affluent usually want to take over these lands. Therefore, under guises including the need to undertake redevelopment, promote highest and best use of land and non-compliance with allocation and lease conditions like non-payments of periodic ground rents, the poor are compelled to vacate these lands under arragements, such as sale of the lands at give away prices, allocation of alternative lands, and eviction.

\section{Women Access to Lands}

Gender was not perceived as a significant bar to land access. This is due to the increasing role of financial capacity as a major determinant to land access. However, some of the participants particularly the civic leaders noted the possibility of the existence of discrimination on the basis of gender. They said that there are still some limitations on women ownership of land in certain traditional communities in the country and that whilst these limitations may not necessarily bar women from owning land, they make them second fiddle to men. It further emerged that the continuous existence of these limitations is rooted in keeping family traditions and the fact that they inure to the benefit of men who often wield the most influence in the relevant communities.

\section{Security of Land Tenure}

All the participant groups agreed that lands obtained from the formal land delivery system are more secured compared to those from the informal system. This is partly due to the benefit of certification by Government and the vitual absence of multiple sale of the same parcels of land. The balance between the two forms of land grants was neatly encapsulated in the observation by a private sector participant in Enugu as follows: 
Land registration with the Government is slow for both the formal and informal lands but the security of tenure of formal land is more guaranteed than the informal land where cases of multiple sale and encroachment are rife.

The difficulty with identifying the rightful owners and authorised actors, such as leaders of land owning groups and agents, unreasonable terms, as well as the absence of well established mechanism to address post land grants issues were further cited as part of the causes of the tenure security problem. The issue of multiple sales of the same parcel of land was traced to a number of causes. First, it came to the fore that informal land grantors hardly keep proper records of their transaction. Therefore, they often forget that a land, which is the subject matter of a current transaction had already been sold. This finding concurs with what is reported in studies, such as Ikejiorfor et al. (2004) and Ikejiorfor (2006). Secondly, the issue is motivated by greed. It was explained that this often happens where a previously sold land is not developed and another purchaser approaches the grantor with a higher offer or where the grantor had already used the money from the previous sale(s) and he/she is hard pressed with money. It was further explained that multiple sales could arise where proceeds from sales do not benefit all members of a land owning family in which case other members of the family find avenues to sale the land particularly if it is not developed.

\section{Lack of Awareness and Periodic Review of Master Plans}

There was a recognition of a lack of awareness of urban planning, development processes and regulations, and periodic review of existing master plans. Civic leaders, as well as participants from the private sector and the professional bodies particularly emphasised the challenge of 
lack awareness of planning processes. They predominantly attributed it to a lack of or inadequate engagement of urban sector stakeholders in planning and noted such lack of awareness has partly culminated in disregard for planning regulation, an issue which is generally acknowledged in the literature. Also, there was consensus among the participants regarding a lack of period review of existing master plans. A Government participant from Enugu, for instance, noted that apart from a patchy amendment, the master plan for Enugu prepared during the colonial era has not undergone any major revision. Questions were raised about the type and form of existing master plans with doubts as to whether they are culturally sympathetic. These questions stemmed from the observation that most of the master plans in the country were prepared by the colonial administration and the colonialists did so for their own interest. They excluded the traditional areas and did not consult the traditional authorities in the plan preparation. Consequently, the cultural norms and practices of the Nigerian society were not incorporated in these plans. For instance, the participants from Enugu noted that virtually all the informal economic activities, which have always been associated with the indegenes were noted factored in the city's master plan.

\section{Infrastructure Provision}

Consistent with the literature provision of infrastructure was recognised by all the participant groups as one of the biggest challenges across the cities in the country. Infrastructure was seen to be lacking in informal settlements by all the participants and the existing infrastructure was said to be at risk from encroachment by unplanned informal development. Government and the private sector participants further identified that infrastructure is non-existent or of poor quality in some formal settlements despite the stipulations of master plans and good intentions of responsible parties. However, it was noted there have been instances where informal settlements and Government have worked together to provide basic infrastracture and services 
in such setllements. The example of the Emene Community was again cited by the Enugu participants. It was further acknowledged across the participant groups that community selfhelp and the assistance of NGOs are sometimes used to provide basic infrastructure for informal developments. This finding supports findings from previous studies, such as Ibem (2009).

\section{Opportunities}

The findings on the opportunities of the existing planning and governance system focus on individual housing and related developments, and major development initiatives taking place across the country. These are presented below:

\section{Individual Housing and Related Developments}

Although access to formal developable land remains a challenge, the participants noted that the informal land delivery system provides avenue for the greater majority of the urban population to access lands for housing and related developments, such as accommodtion for neighbourhood or informal economic activities. There was a consensus among the participants that the majority of the urban development activities taking place in Nigeria occur within the informal planning and governance system, and across the case study cities particularly Enugu and Minna these developments were said to be prevalent in the central areas and virtually all the neigbourhoods. For Abuja, such developments were noted be occuring very fast and settlements, such as Nyanyan, Rubochi and Karo were cited as examples. Thus, the informal planning and governance system continues to fill the void left by the formal planning and governance system. This is through provision of opportunities, such as easy access to land and flexible development processes for the majority of the urban population especially those in the low income group to meet their urban development needs and ultimately their livelihoods. 
These opportunities are important particularly in the face of the on-going urbanisation and rising urban poverty in the country, as well as the inadequacies of the formal system. This supports the views of commentors, such as (Ikejiorfor , 2006; Rakodi, 2007; UN-Habitat, 2014) that suggest that the informal system is relevant in some respects and lessons could be drawn from them for better urban management.

\section{Major Development Initiatives}

The participants identified the emergence of some major land development initiatives across major cities in the country. These projects were seen to provide opportunities to support the delivery of the functions of the planning and governance system. The projects cut across housing, commercial, transport infrastructure and climate adaption programmes that seek to ensure effective and efficient functioning of the cities to promote socio-economic development. Thus, they are supposed to provide a transformational impact in the urban landscape. Proposed initiatives and projects, such as Abuja Centenary City Project, Kantampe Infrastructure Development, Lagos Urban Transport Project (LUTP), the redevelopment of Makoko, the Calabar Hills, and the medium and large scale developer-built estates and the commercial developments with retail facilities, such as the Legacy Estate, and Palms Ibadan in Ibadan were identified. These projects are a combination of joint venture between the Nigerian Government and the private sector (public-private partnership (PPP)) and purely private sector investment. Further, it emerged that they are partly motivated by favourable investment conditions, such as the on-going urbanisation, and growing young workforce and middle income population, which has culminated in rising levels of demand for various real estate including plush homes, offices and retail shops, and good infrastructure. The participants, however, bemoaned the poor business climate in the country, such as delays relating to registration of businesses, urban crime, power fluctions and outages, traffic congestions and 
other urban challenges discussed previously, which they said could derail the current investment drive.

The participants also observed that the projects could have long term implications for effective planning and urban management. For example, it was acknowledged that the Abjua Centenary City promises to create 50,000 jobs. However, the participants especially those from Abuja expressed that there is little indication of how such development could address the needs of urban residents who are unable to access it for either accommodation or employment.

Additionally, it was noted that the transformative impact that the LUTP can have in unleashing development opportunities, and providing greater and more functional transport options needs to be considered against the planning process they operate within. This stemmed from the observation that the support for reform to achieve broader social and economic objectives will have to integrate these policies with spatial plans for Lagos to adequately coordinate across boundaries and allocate resources. Similarly, it was expressed that the idea to redevelop Makoko to provide infrastructure, such as water, waste water management, solid waste management and social services could attract and cater for the burgeoning middle-class. However, innovation may be required to deliver the project. Consequently, in agreement with the literature, these new and emerging developments, massive in scale and undertaken in partnership with Government have implications for the wider planning and development process. Thus, whilst these developments are examples of urban transformation and tremendous real estate development occurring in Nigerian cities, they may not be fully responsive to the diversity of needs across an urban area, city or region, an issue several commentators in the literature (Gandy 2005, Sawyer 2014, Bloch 2014) acknowledge.

\section{Suggested Solutions}


The participants suggested some solutions to the challenges of the urban planning and governance in Nigeria. These suggestions focused on three main issues namely transperency in formulation and implementation of land allocation policies, support for structured planning and community involvement in planning and governance. The details of the suggestions are presented below:

\section{Transparency in Formulation and Implementation of Land Allocation Policies}

There was a unanimous call for transperency in the formulation and implementation of policies on land allocation process, and the need to make formal lands affordable and accessible to all categories of people. Land allocation committees comprising representatives of various classes in society was recommended.

\section{Support for Structured Planning}

An appetite for structured planning of settlements with consistent application of receptive rules across all stakeholder groups was evident. Participants, including civic leaders were almost unanimous in their support for master plans and clear communication of those plans. This stemmed from the recognition that unplanned settlements lack suitable infrastructure and ad hoc arrangements lead to inequitable distribution of land and resources, as well as increase the tendency for different rules to apply for the rich and the powerful. Participants from the professional bodies and Government went on to suggest greater finance and resources to build capacity to enable implementation of plans. Greater professionalism and the use of modern technology was suggested by participants from the professional bodies. Also, payment of compensation on Government land acquisitions and enforcement measures to ensure development control were suggested.

\section{Community involvement in Planning}


Community involvement and engagement were recommended to improve urban planning and management. However, there were different perspectives on what it meant. The majority of the participants from Government and the professional bodies suggseted a need to educate and instruct communities in pursuit of pre-planned goals. Conversely, a pro-active role was recommended by the civic leaders and the private sector participants. The participants further suggested a greater integration between the formal and informal systems as a means to address the urban planning challenges noting that all can make a meaningful contribution to the debate. This recommendation was suggested from different perspectives. Integration was seen as a way to reduce bureacracy by the private sector participants and those from the professional bodies. However, the civic leaders saw integrated planning systems as a way of keeping traditions and traditional spaces within planned communities, and community leaders as the holders of valuable local knowledge and helping to certify land ownership. The Government participants largely preferred the streamlining of the formal system rather than integrating the formal and informal systems with some of the group members noting the utilisation of the policies of regularisation and "village excision" by the Lagos State Government to grant title to the informal land developers as an example. Integration was, thus, perceived partly as successful provision of planning layouts to developments that were not allocated by Government in response to community approaches without the necessity of re-acquiring land.

\section{Summary and Conclusions}

Growing levels of urbanisation in the face of inadequate provision of infrastructure and extreme climate remain a serious problem in Nigeria as in most SSA countries. The existing urban planning and governance system, which is supposed to help address these issues is largely perceived as weak and, therefore, ineffective. Yet the existing system seems to provide opportunities for urban development. This study explored the challenges and the opportunities 
of the existing urban planning and governance system with the view to providing input for policy direction. The study was based on interview survey of urban sector stakeholders in three Nigerian cities of Abuja, Minna and Enugu.

The study found that formal lands are acquired through Government and that land registration as a legal perfection of ownership to land was universally recognised. However, knowledge as to why and how Government is vested with the authority to grant formal land was not uniform among the participants. Whilst Government and private sector participants demonstrated extensive knowledge of the Government role under reference, such knowledge was patchy among the civic leaders and the participants from the professional bodies. This lack of uniformity in knowledge was also exhibited among the participants with regards to the meaning of urban planning. The foregoing implies that some prominent and influential stakeholders in the urban development processes may after all not be aware of the extant planning and development arrangements. What is even striking is that despite the comprehensive conception of urban planning by the Government and professional bodies' participants, planning in practice is limited to land use distribution issues and enforcement of regulation. However, these functions are not pursued rigorously. This signifies the presence of an inertia, which may be connected to some of the challenges identified by the participants particularly political interference, lack of resources and corruption.

Although examples of collaboration or community involvement in planning and development were cited, different views and experiences were expressed by the participants with a greater number suggesting that community involvement is not a norm. The views expressed by the participants coresponded with what has been reported previously in the literature. However, the differences in views and experiences demonstrate that efforts to increase participation may 
be unco-ordinated and lack uniformity. Whilst this may not augur well for integrated development in the short term, it points to an opportunity and willingness to develop innovative systems from a diversity of examples of good practice. Such proposed innnovative system could be informed by some of the necessary conditions to promote participation, such as communities taking intiative and public authorities being receptive.

Consistent with the literature, it was found that the planning and governance system has several challenges. Lack of access to formal lands by the greater majority of the urban population was noted. Apart from corruption, resource constraints and political interferance, cost and inconveniences, such as bereaucratic delays were found to be major causes of the lack of access to formal lands. These causes were not limited to formal land institutions, but also to planning and land development institutions. These challenges together with non-payment of compensation for Government land acquisition were recognised as partly responsible for the preponderance of informal developments.

The poor's lack of access to formal lands was found to be far worse. This was due to financial cost, lack of awareness about availability and the allocation processes, as well as the poor's inability to hold onto to such lands. The poor's access to informal lands was also found to be decreasing in the face of urbanisation and commodification of lands. This coresponded with findings from recent studies on the subject and needs to be addressed. There was, however, a question around the established view of discrimination against women in terms of access to both formal and informal lands that warrants further investigation. This is because it was found that this is a rapidly changing area with financial capacity increasingly becoming a major determinant of access to land although some traditional communities still have practices that limit women's access to land. 
In corespondance with the literature, tenure to informal lands was noted to be insecured compared to formal lands. This was attributed predominantly to mutiple sale of the same parcels of land. Lack of awareness of planning regulation and processes among the urban population, and periodic review of master plans were identified as a challenge. The lack of awarness of planning regulations and processes, in particular, reaffairm the finding of some influential urban stakeholders not knowing these urban development imperatives. It also brings into sharp focus the need for community participation in planning, which could help to address this challenge. There may, therefore, be a need for communication and engagement of all and sundry in planning to generate wider awareness if ideals of urban planning are to be achieved. Another major challenge was inadequate provision of infrastructure and municipal services. Whereas literature suggests that planned areas are provided with good infrastructure, the picture that emerged from the analysis is that the position is far from clear and that settlements driven by communities and developers, taking advantage of major infrastructure, overlaid by local plans are just as likely to be well serviced. However, this pattern may render the major infrastructure obsolete due to underestimation of capacity.

Despite the foregoing challenges, it became evident that the existing planning and governance arrangement offers avenues for urban development. This is particularly in relation to the comparatively ease with which the greater majority of the urban population is able to access land and undertake housing, as well as related developments to accommodate their socioeconomic activities through informal planning, development and governance arrangements. This concurs with recent evidence on the relevance of the informal urban development system across SSA. Further, emerging major land development initiatives that could support the delivery of the functions of the planning and governance system were identified across major 
cities in the country. These were in the form of new and proposed developments, massive in scale and undertaken in partnership with Government, as well as purely private sector investment. Whilst these developments are envisaged to provide transformational impact, they may not necessarily be fully responsive to the diversity of needs across an urban area, city or region. That said, there was, in the main, a call for transperency in formulation and implementation of land allocation policies, support for structured planning and community involvement in planning and governance to redress the identified challenges. These suggestions appear to be responsive to the inadequacies of the existing planning and governance system as they could promote collective action towards the solution of the problems.

Given the foregoing, it can be surmised that findings from this study provide a strong validation for what has been previously reported in the literature, as well as bring some new insights to bear. In particular, transparency in land allocation, sustained engagement with communities in the form of participatory approaches to planning and governance, and regular revision of master plans could lead to better development outcomes. They also demonstrate that government input especially in the area of infrastructure provision is necessary. It is, thus, imperative for urban governance and management practices to seek to achieve these ideals and ensure that the wider developmental needs of urban residents including those in the informal sector are met. Accordingly, there is a need for a re-think of policies, mechanisms and arrangements for urban land, planning, and governance in Nigerian cities in realistic ways to address the ills of the urban development system and promote the opportunities it offers.

\section{References}

Abubakar, I.M. (2014), 'Abuja city profile', Cities, 41, 81-91. 
Adam, A.G. (2014), 'Informal settlements in the peri-urban areas of Bahir Dar, Ethiopia: An institutional analysis', Habitat International, 43, 90-97.

Adams, P. (2016), 'State(s) of crisis: Sub-national governments in Nigeria', Africa Research Institute, Briefing note 1602.

Adeniyi, P. (2013), Improving Land Sector Governance in Nigeria. Implementation of the Land Governance Assessment Framework. A Synthesis Report, Department of Geography, University of Lagos.

Agunbiade, M.E. and Rajabifard, A. (2013), 'Analysing of inter-agency integration for land delivery in Nigeria: Data, process and policy integration', Proceedings of Global Geospatial Conference, Addis Ababa, Ethiopia, November, 4-8.

Akingbade, A., Navarra, D., Zevenbergen, J. and Georgiadou, Y. (2012), 'The impact of electronic land administration on urban housing development: The case study of the Federal Capital Territory of Nigerian', Habitat International, 36, 324-332.

Aribigbola, A. (2007), 'Urban land use planning, policies and management in Sub Saharan African countries: Empirical evidence from Akure, Nigeria', Report presented at the 4th World Bank Urban Research Symposium, Washington, DC, June, 2007.

Baffour Awuah, K.G. (2016), 'Developing a framework for evaluating equity in informal urban land development system in Sub-Saharan Africa', paper presented at the Sustainable City Conference, Alicante, Spain, July 8-11.

Bloch, R. (2014), Africa's New Suburbs, in Hamel P. and Keil, R. (eds.) Suburban governance: A global view, University of Toronto Press, Toronto. 
Chorkor, B.A. (1993), 'External European influence and indigenous social values in urban development and planning in the Third World: The case of Ibadan, Nigeria', Planning Perspectives, 8, 283-306.

Deininger, K., Hilhorst, T. and Songwe, V. (2014), 'Identifying and addressing land governance constraints to support intensification and land market operation: Evidence from 10 African countries, Food Policy, 48, 76-87.

Egbu, A. U., Olomolaiye, P. and Gameson, R. (2008), 'A Neo-institutional economic critique of the system for allocating urban land and development rights in Nigeria', Habitat International, 32,121-135.

Eko, A.J., Ayama, O.R., Eni, D.I., Eja, E.I. and Esien, O.E. (2012), 'The effects of urban sprawl on peripheral agricultural lands in Calabar, Nigeria', International Review of Social Sciences and Humanities, 2, 68-76.

Gandy, M. (2005), 'Learning from Lagos', New Left Review, 33, 36-52.

Idemudia, U. (2012), 'The resource curse and the decentralisation of oil revenue: The case of Nigeria', Journal of Cleaner Production, 35, 183-193.

Ikejiofor, U. (2006), 'Equity in informal land delivery: Insights from Enugu, Nigeria'. Land Use Policy, 23, 448-459.

Ikejiofor, U.C. (2009), 'Planning within a context of informality: Issues and trends in land delivery in Enugu, Nigeria', Available Online at: www.unhabitat.org/grhs/2009 (Accessed: 27/10/2013).

Ikejiofor, C.U. Nwogu, K.C. and Nwanunobi, C.O. (2004), Informal land delivery processes and access to land for the poor in Enugu, informal land delivery in African cities, 
Working Report 2, University of Birmingham, School of Public Policy, International Development Department, Birmingham.

Nkurunziza, E. (2008), 'Understanding informal urban land access processes from a legal pluralist perspective: The case of Kampala, Uganda', Habitat International, 32, 109120.

Ogbazi, J.U. (2013), 'Alternative planning approaches and the Sustainable Cities Programme in Nigeria', Habitat International, 40, 109-118.

Ogu, V.I. (1999), 'Evolutionary dynamics of urban land use planning and environmental sustainability in Nigeria', Planning Perspectives, 14, 347-368.

Ogu, V.I. (2002), 'Urban residential satisfaction and the planning implications in a developing world context: The example of Benin City, Nigeria', International Planning Studies, 7, $37-53$.

Ogun, T.P. (2010), 'Infrastructure and poverty reduction: Implications for urban development in Nigeria', Urban Forum, 21, 249-266.

Oloyede, S.A.,Iroham, E.O. and Ayedun, C.A. (2011), 'Informal land market: Alternative approach to mass residential housing in South-Western Nigeria', Journal of Geography and Regional Planning 4,598-603.

Rakodi, C. (2007), 'State-society relations in land delivery processes in five African cities: An editorial introduction, International Development Planning Review, 28, 127-136.

Sawyer, L. (2014), 'Piecemeal Urbanisation at the Peripheries of Lagos', African Studies, 73, 271-289. 
UN-Habitat (2014), The state of African cities 2014:Re-imagining sustainable urban transitions, Earthscan, London.

Wekesa, Steyn, G.S. and Otieno, F.A.O. (2013), 'A review of physical and socio-economic characteristics and intervention approaches of informal settlements, Habitat International, 35, 238-245.

World Bank (2014), Doing Business in Nigeria 2014. Understanding Regulations for Small and Medium-Size Enterprises, World Bank, Washington DC.

World Bank (2017), Doing Business: Equal Opportunity for All. Economy Profile: Nigeria, 2017, World Bank, Washington DC. 